\title{
SPECIAL ISSUE - CLINICAL AND PUBLIC LEGAL EDUCATION: RESPONSES TO CORONAVIRUS
}

Hugh McFaul and Francine Ryan, The Open Justice Centre at The Open University Law School, UK.

The following special issue of the journal is published jointly with the International Journal of Public Legal Education. The contents are therefore duplicated online for both publications.

Proverbial wisdom has it that 'its an ill wind that blows nobody any good' and, thankfully, the experiences of the CLE community suggest that this may ring true for pandemics as well as storms. In this special issue the reader will benefit from an initial analysis of the experiences of law teachers living through an unprecedented crisis and grappling with the unexpected requirement to rapidly adjust their practice to continue to meet the needs of both their students and the users of their pro bono legal services. The challenges faced by CLE practitioners are discussed from a variety of perspectives across eight practice reports drawn from the UK, USA and India. Although the difficulties discussed are significant, the responses and novel solutions presented across all the papers attest to the creativity, energy and commitment that is the hallmark of the CLE community, and they point to new pathways for clinics to engage with their communities. 


\section{Editorial}

Our invitation to edit this special edition arose after we submitted an article for publication to the IJCLE in summer 2020, which is now included as our contribution to this edition with the title 'Taking Clinical Legal Education Online: songs of innocence and experience.' This article reflects on our four-year journey towards making clinical legal education accessible to distance learning students at The Open University. Our paper highlights experiments with technology, efforts to foster positive working relationships for remote student teams and how we have tried to reimagine the role law schools can play in promoting the development of legal capabilities in their communities. Professor Elaine Hall recognised that many other law schools were now attempting to adapt their teaching in a similar fashion, but in a considerably compressed timescale, and that this this experience should be highlighted in a special edition of the IJCLE. We were delighted to accept the invitation to guest edit the journal and have benefitted from the insights, reflection and analysis offered in the practice reports submitted for this special pandemic edition.

Codd et al focus their reflections on an innovative prison-based business and tax law clinic run by the University of Central Lancashire. Their discussion highlights the need to take a flexible and solution based approach to the planning and delivery of prison based clinics, not just because of the pressures of the pandemic, but also due to the need to negotiate a shifting landscape of government guidance and changes in priorities of prison and university management. A perspective from India is provided 


\section{Editorial}

by Gigimon and Nandwana. This paper considers how the decision of the Indian judiciary to utilise virtual courts, and how a similar move by the National Legal Aid Service to conduct virtual Lok Adalats, impacts upon clinical legal education in India. The authors propose a working model for how legal aid clinics should respond.

Wallace provides valuable insights from the USA in her article 'Classroom to Cyberspace: preserving Street Law's interactive and student-centered focus during distance learning' around the transfer of street law methodologies into an online setting. The article discusses some of the challenges of recreating the interactive elements of street law that are at the core of its delivery in a virtual environment. Readers will learn a lot about how to adapt their own street law programmes and about the potential to consider new ways of reaching out and engaging schools beyond the borders of the physical classroom.

The pandemic has proved challenging for our students and there is a considerable amount of concern around the impact on mental health, which is why the article from Wapples makes such a valuable contribution to this edition. 'Promoting positive mental health in international postgraduate law students at a time of global uncertainty: a case study from qLegal at Queen Mary University of London' provides a practical example of what can be done to support students to help overcome feelings of isolation and maximise engagement in a time of uncertainty. Readers with international students will find this article particularly interesting as it offers insights 


\section{Editorial}

into the specific challenges they face and the importance of building networks of support.

Matt et al argue that despite the negative impact of the pandemic, clinical legal education programmes can find new and sustainable ways to deliver legal services to their clients. Their article explores the University of Exeter's transformation from an in person to a remote delivery service and offers insights into the lessons learned. What comes across strongly is no matter what the mode of delivery, the heart of all clinical work is the human connection.

Setting up a new clinic is challenging, but to do that during a pandemic only intensifies the challenge. In 'Royal Holloway University of London and the Afghanistan and Central Asian Association: New Partnerships and Challenges during COVID-19 in the Clinical Legal World' Antoniou et al share their experiences of adapting an emerging service in a time of uncertainty. This article shows the power of partnership to tackle inequality and respond to high levels of unmet legal need that impact on marginalised communities. The experience of setting up a new clinic and then dealing with the challenge of the pandemic is also the focus of papers by Thurston and Kirsch (University of Hertfordshire) and Howells (University of Derby). Both papers argue for the value of the continued use of virtual clinics in addition to face to face engagement.

Many of us working in law clinics have a legal practice background and some find the prospect of writing for journals to be a little daunting! We are really pleased that this 


\section{Editorial}

edition has encouraged a number of colleagues to submit their work for publication to the journal for the first time. We hope that the discussions presented in these papers will encourage others to share their experiences by submitting work for future editions. 